\title{
Secondary overtriage of pediatric neurosurgical trauma at a Level I pediatric trauma center
}

\author{
Charles E. Mackel, MD, JD, ${ }^{1}$ Brent C. Morel, MD, Jesse L. Winer, MD, ${ }^{1}$ Hannah G. Park, BA, ${ }^{1}$ \\ Megan Sweeney, BS, ${ }^{1}$ Robert S. Heller, MD, ${ }^{1}$ Leslie Rideout, FNP, PhD, ${ }^{1}$ Ron I. Riesenburger, MD, ${ }^{1}$ \\ and Steven W. Hwang, MD²
}

\begin{abstract}
${ }^{1}$ Department of Neurosurgery, Tufts Medical Center and Floating Hospital for Children, Boston, Massachusetts; and ${ }^{2}$ Shriners Hospitals for Children—Philadelphia, Philadelphia, Pennsylvania
\end{abstract}

\begin{abstract}
OBJECTIVE The authors reviewed the transfer requests for isolated pediatric traumatic brain injuries (TBIs) at a Level I/II facility with the goal of identifying clinical and radiographic traits associated with potentially avoidable transfers that could be safely managed in a non-tertiary care setting.

METHODS The authors conducted a retrospective study of patients $<18$ years of age classified as having TBI and transferred to their Level I tertiary care center over a 12-year period. The primary outcome of interest was identifying potentially avoidable transfers, defined as transfers of patients not requiring any neurosurgical intervention and discharged 1 hospital day after admission.

RESULTS Overall, $70.8 \%$ of pediatric patients with isolated TBI did not require neurosurgical intervention or monitoring, indicating an avoidable transfer. Potentially avoidable transfers were associated with outside hospital imaging that was negative $(86 \%)$ or showed isolated, nondisplaced skull fractures $(86 \%)$ compared to patients with cranial pathology $(53.8 \%, p<0.001)$ as well as age $\leq 6$ years $(81 \%$ [negative imaging/isolated, nondisplaced fractures] vs $54 \%$ [positive cranial pathology], $p<0.001)$. The presence of headaches, nonfocal deficits, and loss of consciousness were associated with necessary transfer $(p<0.05)$. Patients with potentially avoidable transfers underwent frequent repeat $C T$ studies $(19.1 \%)$ and admissions to the pediatric intensive care unit (55.9\%) but at a lower rate than those whose transfers were necessary $(p<0.001)$. Neurosurgical interventions occurred in $11 \%$ of patients with cranial pathology, which accounted for $17.9 \%$ of necessary transfers and $5.2 \%$ of all transfers.

CONCLUSIONS In the authors' region, potentially up to $70 \%$ of interfacility transfers for pediatric brain trauma in the absence of other systemic injuries warranting surgical intervention may not require neurosurgical intervention and could be managed locally. No patients transferred with isolated, nondisplaced skull fractures or negative CT scans required neurosurgical intervention, and $86 \%$ were discharged the day after admission. In contrast, $11 \%$ of patients with CT scans indicative of cranial pathology required neurosurgical intervention. Age $>6$ years, loss of consciousness, and nonfocal deficits were associated with a greater likelihood of needing a transfer. Further studies are required to clarify which patients can be managed at local institutions, but referring centers should practice overcaution given the potential risks.

https://thejns.org/doi/abs/10.3171/2018.5.PEDS182
\end{abstract}

KEYWORDS head injury; pediatric; transfer; triage; trauma

$\mathrm{L}$ EVEL I and II trauma centers receive patients by either direct transport or transfer to offer immediate access to centralized and comprehensive regional specialty trauma services. For designation, Level I and Level II trauma services require the same level of clinical care, with Level I trauma centers additionally required to meet admission volume requirements, maintain a surgically directed critical care service as well as a residency program, and perform trauma research. ${ }^{1}$ Moderately to severely injured patients treated at Level I trauma centers either through direct transport or transfer may have a $20 \%-38 \%$ reduction in mortality rate compared to cohorts

ABBREVIATIONS ATC = adult trauma center; ED = emergency department; GCS = Glasgow Coma Scale; ISS = Injury Severity Score; LOS = length of stay; PICU = pediatric intensive care unit; PTC = pediatric trauma center; TBI = traumatic brain injury

SUBMITTED January 16, 2018. ACCEPTED May 10, 2018.

INCLUDE WHEN CITING Published online June 29, 2018; DOI: 10.3171/2018.5.PEDS182. 
treated at nontrauma or nontertiary centers. ${ }^{27,30}$ For the most severe injuries, Level I centers may offer improved outcomes compared to Level II trauma centers, ${ }^{10,18}$ though Level II trauma centers may still offer improved outcomes relative to nontertiary trauma centers. ${ }^{16}$

Due to the superior outcomes of severely injured patients treated at higher-level trauma centers, minimally injured patients who could be managed at lower-level centers are often directly transported to higher-level centers, known as "primary overtriage." When a minimally injured patient is initially admitted to a lower-level center, unnecessary transfer following primary survey and stabilization to a higher-level facility is known as "secondary overtriage." ${ }^{20}$ To achieve undertriage of $<1 \%$ of preventable deaths and $<5 \%$ of major traumas (as measured by Injury Severity Score [ISS]), primary overtriage of $25 \%-$ $35 \%$ of patients is typically viewed as reasonable. ${ }^{1}$ However, the impact of both primary and secondary overtriage of patients is a severe depletion of resources, including neurosurgical coverage, ${ }^{11,13}$ with the mean cost of interfacility overtriage ranging between $\$ 9206$ to $\$ 12,549$ per transfer. ${ }^{41,43}$

Overutilization of neurosurgical coverage may be particularly acute in the pediatric transfer population. In one study, $64 \%$ of preventable transfers in the pediatric population implicated traumatic brain injury (TBI). ${ }^{15}$ Additional studies identified that one quarter to one half of unnecessary pediatric interfacility transfers utilized neurosurgical evaluation, ${ }^{15,24}$ and a neurological consult request represented increased odds (OR 2.61) of an unnecessary transfer. ${ }^{24}$ This secondary overtriage may follow from an uncertainty with recognizing pediatric patients with TBI who do not need a higher level of care. Consequently, we reviewed the transfer requests for isolated pediatric TBI over a 12-year period at a Level I facility with the goal of identifying clinical and radiographic traits associated with potentially avoidable transfers.

\section{Methods}

We conducted an IRB-approved retrospective review of all consecutive documented requests for interhospital patient transfer due to TBI at the Kiwanis Pediatric Trauma Institute at the Floating Hospital for Children at Tufts Medical Center from January 1, 2002, to October 30, 2014. This facility is a Level I pediatric trauma center that was briefly Level II from 2008 to 2011 following the institution of volume requirements by the American College of Surgeons. These documented requests were contained within our facility's prospectively gathered registry of adult and pediatric trauma incidents. We used our facility's code for TBI to identify potentially relevant cases in the pediatric population ( $<18$ years). We then performed chart reviews to extract details regarding each transfer center event. As we function as a tertiary care center, patients were not subsequently transferred out to another hospital.

The primary outcome of interest was a "potentially avoidable transfer." A potentially avoidable transfer was defined as a patient $<18$ years of age who underwent head CT scanning prior to transfer and who was discharged the day following admission to the receiving facility without neurosurgical intervention. A "necessary transfer" failed to meet these criteria. A "neurosurgical intervention" was defined as any invasive neurosurgical procedure, such as a craniotomy or placement of an intracranial pressure monitoring system.

We excluded patients who did not receive a head CT scan at the transferring hospital and patients whose primary reason for transfer was status epilepticus or nonaccidental traumas, because social and medical factors would likely confound the reason for extended hospital length of stay (LOS). To maintain the emphasis on head injury, we additionally excluded patients requiring nonneurological surgery. Secondary outcomes of interest included repeat CT imaging, pediatric intensive care unit (PICU) admission, and PICU admission beyond 1 day.

Charts were reviewed for patient demographics, mechanism of injury, time of arrival to outside hospital, method of transfer, outside diagnostic imaging, and outside clinical assessment, including ISS and Glasgow Coma Scale (GCS) score. We noted whether emesis, seizures, loss of consciousness, and focal or nonfocal neurological deficits were observed following injury. For verbal patients (age $\geq$ 2 years), we included whether amnesia or headaches were experienced. We additionally recorded neurosurgical interventions, length of hospital LOS, PICU admission, and repeat CT within 24 hours of admission. Radiological findings were subdivided into whether they revealed significant or suspected cranial pathology; isolated linear, nondisplaced skull fracture; or negative imaging (i.e., no abnormal findings). Significant cranial pathology included epidural or subdural hematomas, hemorrhage, pneumocephalus, depressed skull fractures, or a subgaleal hematoma in patients $\leq 3$ months of age.

Statistical analysis was performed using IBM Statistics SPSS 24.0 (IBM Corporation). Continuous variables were analyzed with Student t-tests, while categorical variables were analyzed with a chi-square test or Fisher's exact test as appropriate. Descriptive statistics were computed as necessary and represented as mean \pm SD. A p value $<0.05$ was considered significant.

\section{Results}

Retrospective review identified 1098 patients with pediatric trauma over a 12-year period who were transferred. Of these, 192 transfers met criteria for analysis as a potentially avoidable transfer (PAT) or necessary transfer (NT) for isolated head trauma. Of the 192 transfers, 136 were potentially avoidable $(70.8 \%)$.

Characteristics of patients at the point of transfer are listed in Table 1. The mean age of transferred patients was $5.3 \pm 5.4$ years (range 1.6 weeks to 17 years). Sixty-one percent of patients (118/192) were male. The primary mechanism of transfer was by ambulance $(86.5 \%)$. Almost half of the patients $(87 / 192,45.5 \%)$ arrived at the outside hospital between the hours of 18:00 and 23:59. At the transferring hospital, 93\% (170/183) of patients were assessed as having an average GSC sore of 13-15 and an ISS of $7.1 \pm 5.9$. Of patients' clinical signs and symptoms (Table 2), emesis was the most common overall, occurring in $39.1 \%$ of patients, whereas headache was the most com- 
TABLE 1. Characteristics of patients at point of transfer

\begin{tabular}{|c|c|c|c|c|}
\hline \multirow[b]{2}{*}{ Variable/Subvariable } & \multicolumn{3}{|c|}{ Transfers } & \multirow[b]{2}{*}{$\mathrm{p}$ Value } \\
\hline & All $(n=192)$ & Potentially Avoidable $(n=136)$ & Necessary $(n=56)$ & \\
\hline Mean age $\pm S D$, yrs & $5.3 \pm 5.4$ & $4.3 \pm 5.0$ & $7.8 \pm 5.4$ & $<0.001$ \\
\hline$\leq 6$ & $121(63.0 \%)$ & $98(72.1 \%)$ & $23(41.1 \%)$ & $<0.001$ \\
\hline$>6$ & $71(37.0 \%)$ & $38(27.9 \%)$ & $33(58.9 \%)$ & \\
\hline Sex & & & & 0.644 \\
\hline Male & $118(61.5 \%)$ & $85(62.5 \%)$ & $33(58.9 \%)$ & \\
\hline Female & $74(38.5 \%)$ & $51(37.5 \%)$ & $23(41.1 \%)$ & \\
\hline Method of transfer & & & & 0.415 \\
\hline Private car & $4(2.1 \%)$ & $4(2.9 \%)$ & $0(0 \%)$ & \\
\hline Ambulance & $166(86.5 \%)$ & $116(85.2 \%)$ & $50(89.3 \%)$ & \\
\hline Helicopter & $22(11.5 \%)$ & $16(11.8 \%)$ & $6(10.7 \%)$ & \\
\hline Arrival time at outside hospital & & & & 0.234 \\
\hline $0: 00-5: 59$ & $7(3.7 \%)$ & $7(5.2 \%)$ & $0(0 \%)$ & \\
\hline $6: 00-11: 59$ & $32(16.8 \%)$ & $22(16.3 \%)$ & $10(18.2 \%)$ & \\
\hline $12: 00-17: 59$ & $64(33.7 \%)$ & $48(35.5 \%)$ & $16(29.1 \%)$ & \\
\hline $18: 00-23: 59$ & $87(45.5 \%)$ & $58(43.0 \%)$ & $29(52.7 \%)$ & \\
\hline GCS score at outside hospital & & & & 0.001 \\
\hline $13-15$ & $170(92.9 \%)$ & $127(98.4 \%)$ & $43(79.6 \%)$ & \\
\hline $9-12$ & $5(2.7 \%)$ & $1(0.78 \%)$ & $4(7.4 \%)$ & \\
\hline $3-8$ & $8(4.4 \%)$ & $1(0.78 \%)$ & $7(13.0 \%)$ & \\
\hline
\end{tabular}

Values are the number (\%) of patients unless otherwise specified.

mon clinical manifestation of brain injury among the verbal cohort, at $54.3 \%$. Focal neurological deficits, including transient deficits, occurred in $4.7 \%$ of patients, while nonfocal deficits manifested in $22.9 \%$.

Cranial pathology was identified in $47.4 \%$ (91/192) of patients, whereas isolated linear skull fractures were present in $22.4 \%$ (43/192). Imaging was negative for either fractures or intracranial pathology in $30.2 \%(58 / 192)$ of patients (Table 3). Thirty-four percent (65/192) of patients underwent repeat CT. The mean hospital LOS was $1.7 \pm$ 2.8 days (range 1-34 days). One hundred twenty-two patients $(63.5 \%)$ were admitted to a PICU for an average of $1.0 \pm 2.7$ days (range $0-34$ days). Ten (5.2\%) patients required neurosurgical intervention (Table 4).

Fifty-six percent of PATs were admitted to the PICU, a lower rate than NTs $(82.1 \%, \mathrm{p}<0.001)$ but constituting
$62.2 \%$ of total PICU admissions (76/122). NTs were admitted to the PICU for an average of $2.2 \pm 4.8$ days and remained in the hospital for an average of $3.4 \pm 4.8$ days. Ten of 56 NTs (17.9\%) needed neurosurgical intervention (Table 4).

\section{Primary Outcome}

\section{Clinical Characteristics}

The mean age of patients who underwent PATs was younger than that of the NTs $(4.3 \pm 5.0$ years vs $7.8 \pm 5.4$, respectively; $p<0.001)$. Patients $\leq 6$ years old comprised a greater percentage of PATs (72.1\%) than NTs (41.1\%) (p $<0.001$ ) (OR 3.7, 95\% CI 1.93-7.09) (Tables 1 and 5). A GCS score of 13-15 at the transferring hospital comprised a higher proportion of PATs than NTs $(98.4 \%$ vs $79.6 \%$,

TABLE 2. Summary of clinical signs and symptoms

\begin{tabular}{lccrc}
\hline & \multicolumn{3}{c}{ Transfers } \\
\cline { 2 - 4 } \multicolumn{1}{c}{ Variable } & All $(\mathrm{n}=192)$ & Potentially Avoidable $(\mathrm{n}=136)$ & Necessary $(\mathrm{n}=56)$ & $\mathrm{p}$ Value \\
\hline Headache (>2 yrs) & $63(54.3 \%)$ & $33(45.8 \%)$ & $30(68.2 \%)$ & 0.022 \\
\hline Amnesia (>2 yrs) & $24(20.2 \%)$ & $13(18.1 \%)$ & $11(25.6 \%)$ & 0.352 \\
\hline Loss of consciousness & $53(27.6 \%)$ & $26(19.1 \%)$ & $27(48.2 \%)$ & $<0.001$ \\
\hline Emesis & $75(39.1 \%)$ & $48(35.3 \%)$ & $27(48.2 \%)$ & 0.106 \\
\hline Seizure & $11(5.7 \%)$ & $7(5.1 \%)$ & $4(7.1 \%)$ & 0.733 \\
\hline Focal neurological deficit & $9(4.7 \%)$ & $5(3.7 \%)$ & $4(7.1 \%)$ & 0.45 \\
\hline Nonfocal neurological deficit & $44(22.9 \%)$ & $23(16.9 \%)$ & $21(37.5 \%)$ & 0.003 \\
\hline
\end{tabular}

Values are the number (\%) of patients unless otherwise specified. 
TABLE 3. Outside hospital imaging results

\begin{tabular}{|c|c|c|c|c|}
\hline \multirow[b]{2}{*}{ Variable/Subvariable } & \multicolumn{3}{|c|}{ Transfers } & \multirow[b]{2}{*}{$\begin{array}{c}p \\
\text { Value }\end{array}$} \\
\hline & $\begin{array}{c}\text { All } \\
(n=192)\end{array}$ & $\begin{array}{c}\text { Potentially } \\
\text { Avoidable } \\
(n=136)\end{array}$ & $\begin{array}{l}\text { Necessary } \\
(n=56)\end{array}$ & \\
\hline Outside imaging finding & & & & $<0.001$ \\
\hline Cranial pathology & $91(47.4 \%)$ & $49(36.2 \%)$ & $42(75 \%)$ & \\
\hline $\begin{array}{l}\text { Isolated linear skull } \\
\text { fracture }\end{array}$ & $43(22.4 \%)$ & $37(27.2 \%)$ & $6(10.7 \%)$ & \\
\hline Negative & $58(30.2 \%)$ & $50(36.8 \%)$ & $8(14.3 \%)$ & \\
\hline
\end{tabular}

Values are the number (\%) of patients unless otherwise specified.

respectively; $p<0.001)$. Sex, method of transfer, and time of outside hospital arrival did not differ between the cohorts (Table 1).

Loss of consciousness and nonfocal neurological deficits were more common among NTs $(48.2 \%$ vs $19.1 \%$, p < $0.001 ; 37.5 \%$ vs $16.9 \%$, respectively; $p=0.003$ ) than PATs (Table 2). Decreased odds of a PAT were associated with the absence of loss of consciousness (OR $0.25,95 \%$ CI $0.13-0.5, \mathrm{p}<0.001$ ) or nonfocal deficits (OR $0.34,95 \%$ CI $0.17-0.68, \mathrm{p}=0.003$ ) (Table 5). Among the verbal group, headaches were also more common in those with NTs $(68.2 \%$ vs $45.8 \%, p=0.022)$. The occurrence of seizures, emesis, or amnesia did not reliably distinguish one cohort from the other, while the sample size for focal deficits was small (Table 2).

\section{Outside Imaging}

PATs and NTs differed in their frequency of cranial pathology, isolated linear skull fractures, and negative imaging on outside hospital imaging $(\mathrm{p}<0.001)$ (Table 3$)$. The majority of patients with NTs had cranial pathology (75\%), whereas those with PATs were more evenly distributed among negative imaging (36.8\%), isolated skull fractures $(27.2 \%)$, and cranial pathology (36.2\%). Compared to intracranial pathology, isolated skull fractures and negative imaging more accurately predicted PATs (OR 5.3, 95\% CI 2.64-10.71, $\mathrm{p}<0.001)$, whereas isolated skull fractures

\section{TABLE 4. Secondary outcomes: Tufts}

\begin{tabular}{lcccc}
\hline & \multicolumn{4}{c}{ Transfers } \\
\cline { 2 - 4 } \multicolumn{1}{c}{ Outcome } & $\begin{array}{c}\text { Potentially } \\
\text { Avoidable } \\
(n=192)\end{array}$ & $\begin{array}{c}\text { Necessary } \\
(n=136)\end{array}$ & $\begin{array}{c}p \\
(n=56)\end{array}$ & Value \\
\hline Repeat CT & $65(33.9 \%)$ & $26(19.1 \%)$ & $39(69.6 \%)$ & $<0.001$ \\
\hline Mean hospital days & $1.7 \pm 2.8$ & $3.4 \pm 4.8$ & \\
& $(1-34)$ & & & \\
\hline PICU admit & $122(63.5 \%)$ & $76(55.9 \%)$ & $46(82.1 \%)$ & $<0.001$ \\
\hline Mean PICU days & $1.0 \pm 2.7$ & & $2.2 \pm 4.8$ & \\
& $(0-34)$ & & & \\
\hline Neurosurgical & $10(5.2 \%)$ & & $10(17.9 \%)$ & \\
intervention & & & & \\
\hline
\end{tabular}

Admit = admission.

Values are the number (\%) of patients or mean \pm SD (range).
TABLE 5. Selected odds ratios

\begin{tabular}{llr}
\hline \multicolumn{1}{c}{ Variable } & PATs, OR $(95 \% \mathrm{Cl})$ & p Value \\
\hline Negative for isolated skull fracture & $5.3(2.64-10.71)$ & $<0.001$ \\
\hline Cranial pathology & $0.19(0.09-0.38)$ & $<0.001$ \\
\hline$\leq 6$ yrs of age & $3.7(1.93-7.09)$ & $<0.001$ \\
\hline Headache $(>2$ yrs) & $0.39(0.18-0.86)$ & 0.022 \\
\hline Loss of consciousness & $0.25(0.13-0.5)$ & $<0.001$ \\
\hline Nonfocal deficits & $0.34(0.17-0.68)$ & 0.003 \\
\hline
\end{tabular}

and negative imaging had a similar proportion of PATs ( $86 \%$ vs $86 \%, p=0.98$ ).

\section{Secondary Outcomes \\ Clinical Characteristics}

Secondary outcomes with respect to clinical findings are presented in Table 6 . Repeat imaging was associated with patients $>6$ years of age $(47.9 \%$ vs $25.6 \%, p=0.003)$, the presence of headache $(47.6 \%$ vs $26.4 \%, \mathrm{p}=0.022)$, and nonfocal deficits $(54.5 \%$ vs $27.7 \%, \mathrm{p}<0.001)$. Extended PICU stay was associated with age $>6$ years $(26.8 \%$ vs $5.8 \%, \mathrm{p}<0.001)$, loss of consciousness $(24.5 \%$ vs $9.4 \%$, p $=0.009)$, nonfocal deficit $(29.5 \%$ vs $8.8 \%, \mathrm{p}<0.001)$, and a trend toward emesis $(20 \%$ vs $9.4 \%, p=0.051)$. Neurosurgical intervention tended toward association with altered mental status $(11.4 \%$ vs $3.4 \%, \mathrm{p}=0.051)$.

\section{Imaging}

Secondary outcomes with respect to imaging are presented in Table 7. Subanalysis revealed that the presence of cranial pathology was associated with a higher rate of repeat advanced imaging (51.6\%), PICU admission $(83.5 \%)$, extended PICU stay (25.3\%), and neurosurgical intervention $(11.0 \%)$ than isolated skull fractures or negative imaging $(\mathrm{p}<0.01)$. Isolated skull fractures and negative imaging did not differ among these categories, except that patients with isolated skull fractures had a higher frequency of PICU admissions (60.5\% vs $34.5 \%, \mathrm{p}=0.01$ ).

\section{Discussion}

In our population of children with TBI, we observed that $70.8 \%$ of interfacility transfers were potentially avoidable secondary triages, a markedly higher rate than in previous studies. In the adult or general population, secondary overtriage rates have ranged from $23.8 \%$ to $38 \%$ of patients. ${ }^{8,41,43}$ Although the overall secondary overtriage rate is only slightly higher among pediatric patients (age $<15$ or $<18$ years), ranging from $19 \%$ to $49 \%,{ }^{15,17,20,25,28 \text {, }}$ ${ }^{31,41}$ analyses comparing the adult and pediatric secondary overtriage rates within the same population revealed that children are 2 to 4.5 times more likely to be transferred unnecessarily than adults. ${ }^{31,41}$ These transfer rates typically represent the proportion of unnecessary transfers from the vantage point of the receiving hospital; from the viewpoint of the transferring hospital, only $9.8 \%$ of adult transfers ${ }^{9}$ and $18 \%$ of pediatric transfers ${ }^{24}$ are potentially avoidable.

Our high rate of PATs may have followed from our 
TABLE 6. Secondary outcomes by age and clinical findings

\begin{tabular}{|c|c|c|c|c|}
\hline Variable & Repeat CT & ICU Admit & ICU >24 Hrs & Neurosurgical Intervention \\
\hline \multicolumn{5}{|l|}{ Age } \\
\hline$\leq 6 \mathrm{yrs}$ & $31(25.6 \%), p=0.003$ & $71(58.7 \%)$ & $7(5.8 \%), p<0.001$ & $4(3.3 \%)$ \\
\hline$>6$ yrs & $34(47.9 \%)$ & $51(71.8 \%)$ & $19(26.8 \%)$ & $6(8.5 \%)$ \\
\hline \multicolumn{5}{|c|}{ Headache (>2 yrs) } \\
\hline Yes & $30(47.6 \%), p=0.022$ & $42(66.7 \%)$ & $15(23.8 \%)$ & $3(4.8 \%)$ \\
\hline No & $14(26.4 \%)$ & $32(60.4 \%)$ & $7(13.2 \%)$ & $4(7.5 \%)$ \\
\hline \multicolumn{5}{|l|}{ Amnesia (>2 yrs) } \\
\hline Yes & $9(37.5 \%)$ & $18(75.0 \%)$ & $6(25.0 \%)$ & $2(8.3 \%)$ \\
\hline No & $34(37.4 \%)$ & $55(60.4 \%)$ & $15(16.5 \%)$ & $5(5.5 \%)$ \\
\hline \multicolumn{5}{|c|}{ Loss of consciousness } \\
\hline Yes & $22(41.5 \%)$ & $40(75.5 \%), p=0.044$ & $13(24.5 \%), p=0.009$ & $5(9.4 \%)$ \\
\hline No & $43(30.9 \%)$ & $82(59 \%)$ & $13(9.4 \%)$ & $5(3.6 \%)$ \\
\hline \multicolumn{5}{|l|}{ Emesis } \\
\hline Yes & $25(33.3 \%)$ & $49(65.3 \%)$ & $15(20.0 \%), p=0.051$ & $5(6.7 \%)$ \\
\hline No & $40(34.2 \%)$ & $73(62.4 \%)$ & $11(9.4 \%)$ & $5(4.3 \%)$ \\
\hline \multicolumn{5}{|l|}{ Seizures } \\
\hline Yes & $3(27.3 \%)$ & $6(54.5 \%)$ & $2(18.2 \%)$ & $2(18.2 \%), p=0.104$ \\
\hline No & $62(34.3 \%)$ & $116(64.1 \%)$ & $24(13.3 \%)$ & $8(4.4 \%)$ \\
\hline \multicolumn{5}{|l|}{ Focal deficit } \\
\hline Yes & $5(55.6 \%)$ & $6(66.7 \%)$ & $3(33.3 \%)$ & $0(0 \%)$ \\
\hline No & $60(32.8 \%)$ & $116(63.4 \%)$ & $23(12.6 \%)$ & $10(5.5 \%)$ \\
\hline \multicolumn{5}{|l|}{ Nonfocal deficit } \\
\hline Yes & $24(54.5 \%), p<0.001$ & $28(63.6 \%)$ & $13(29.5 \%), p<0.001$ & $5(11.4 \%), p=0.051$ \\
\hline No & $41(27.7 \%)$ & $94(63.5 \%)$ & $13(8.8 \%)$ & $5(3.4 \%)$ \\
\hline
\end{tabular}

Values are the number (\%) of patients.

definition of PAT, which was not limited by ISS score, critical care admission, or repeat imaging. Heterogeneous definitions of secondary overtriage among prior studies have limited comparison of overtriage rates. Previous analyses have defined a PAT as requiring some configuration of an ISS of $<9,{ }^{20}<10,,^{8,43}$ or without reference to ISS: $, 915,17,25,26,31,41$ discharge within $12,{ }^{17} 24,{ }^{20,25,28,31,43} 36,{ }^{15}$ or $48^{8,9,26,41}$ hours; and nonreceipt of an "operation," $8,9,15,20,26,31$, ${ }^{41,43}$ which can denote an operating room-level intervention ${ }^{43}$ any additional medical or surgical intervention, ${ }^{17}$ or select procedures. ${ }^{28}$ Additional criteria, such as no critical care admission ${ }^{20}$ or advanced imaging studies,${ }^{15}$ have also been requirements of a PAT. Modest variations in criteria can drastically change results: Ciesla et al. ${ }^{8}$ calculated that broadening their ISS criterion from $<10$ to $<16$ increased the secondary overtriage, comprising their hospital's total trauma care from $9 \%$ to $19 \%$. This variability highlights the need for a shared definition of secondary overtriage among studies.

The pediatric patients with brain injury in our study may have been aggressively triaged because, although contested, ${ }^{32,45}$ a growing body of literature suggests that pediatric patients benefit from triage to pediatric trauma centers (PTCs) compared to adult trauma centers (ATCs) or ATCs with added pediatric qualifications. ${ }^{2,36,40,46}$ These outcome discrepancies have been attributed to the injury patterns and treatment requirements unique to young children with whom nonpediatric physicians may be less experienced. ${ }^{21,34,36}$ These mortality benefits may be increased further in children $\leq 5$ years of age ${ }^{40}$ which may explain the higher likelihood of children $\leq 6$ years among avoidable transfer requests (OR 3.7, 95\% CI 1.93-7.09, p $<0.001)$. In addition to the potential benefit of aggressive triage of young patients to PTCs, another contributing fac-

TABLE 7. Secondary outcomes by outside imaging result

\begin{tabular}{|c|c|c|c|c|}
\hline Finding & $\begin{array}{c}C T \\
(p<0.001)\end{array}$ & $\begin{array}{c}\text { ICU } \\
\text { Admit* }^{*} \\
(p<0.001)\end{array}$ & $\begin{array}{c}I C U>24 \\
\text { Hrs } \\
(p<0.001)\end{array}$ & $\begin{array}{c}\text { Neurosurgical } \\
\text { Intervention } \\
(p=0.003)\end{array}$ \\
\hline $\begin{array}{l}\text { Cranial pathol- } \\
\text { ogy }(n=91)\end{array}$ & $47(51.6 \%)$ & 76 (83.5\%) & $23(25.3 \%)$ & \\
\hline $\begin{array}{l}\text { Isolated skull } \\
\text { fracture } \\
(n=43)\end{array}$ & $8(18.6 \%)$ & $26(60.5 \%)$ & $3(4.7 \%)$ & $0(0.0 \%)$ \\
\hline $\begin{array}{l}\text { Negative imag- } \\
\text { ing }(n=58)\end{array}$ & $10(17.2 \%)$ & $20(34.5 \%)$ & $1(1.7 \%)$ & $0(0.0 \%)$ \\
\hline \multicolumn{5}{|c|}{$\begin{array}{l}\text { Values are the number }(\%) \text { of patients. } \\
\text { * Patients with cranial pathology were admitted to the ICU at a higher rate } \\
\text { than those with an isolated skull fracture }(p=0.003) \text { and negative imaging } \\
\text { ( } p<0.001) \text {, and patients with an isolated skull fracture were admitted at a highe } \\
\text { rate than those with negative imaging }(p=0.01) \text {. }\end{array}$} \\
\hline
\end{tabular}


tor to overtriage in the pediatric population may be general physician unfamiliarity and discomfort with younger age groups. Gattu et al. ${ }^{17}$ noted that transfers from non-pediatric emergency department (ED) physicians were much more likely to be rapidly discharged than pediatric ED physicians (53.4\% vs. $29.7 \%$ ), consistent with Mohr et al..$^{28}$ As ours was a retrospective study, we were unable to assess what portion of patients came from facilities with pediatric qualifications, but the lower rate of extended LOS among patients $\leq 6$ years old compared to older children suggested that observation and monitoring at a high-level pediatric facility may have been a principal motivation for transfer in this age group.

We limited our study population to instances of pediatric TBI, which may have further contributed to our high avoidable transfer rate, as the mortality benefit of transfer to PTCs derives in part from improved outcomes of pediatric head trauma cases, ${ }^{2}$ which Potoka et al. ${ }^{36}$ correlated to the increased intervention rates in moderate-to-severe head injuries at PTCs. Li et al. ${ }^{25}$ observed that among pediatric patients received via transfer with a diagnosis code of TBI, $50 \%$ of admissions were discharged within 24 hours. In contrast, Fenton et al..$^{15}$ reported that only $31.3 \%$ of head injury transfers were preventable. However, both Fenton et al. ${ }^{15}$ and Li et al. ${ }^{25}$ included head injuries that co-occurred with multisystem trauma within their analyses, which may have depressed the rate preventable transfer rate. Moreover, Fenton et al. ${ }^{15}$ defined receipt of additional advanced imaging as justifying a necessary transfer, and only $61 \%$ of all transfers had received prior CT imaging, with prior receipt of head CTs more common among preventable transfers than unpreventable transfers (65\% vs. $45 \%$ ), indicating that some unscanned patients may have been transferred to be imaged at the receiving facility. Utilizing Fenton's criteria, nearly $20 \%$ of PATs would have been reclassified as necessary in our study. From the perspective of the referring hospital, it has been shown that head CT prior to pediatric transfer reduces the odds of unnecessary transfer (OR 0.33), ${ }^{24}$ an observation consistent with studies involving adult populations (OR 0.30-0.49). ${ }^{9,26}$

We limited our study population to individuals with imaging because we suspected the primary predictor of an avoidable transfer would be pretransfer CT results, and interpreting the need for transfer in light of the outside hospital CT results would best reflect clinical practice. In point of fact, we observed that $86 \%$ of both patients with isolated, nondisplaced skull fractures and patients who did not undergo imaging were discharged within 1 hospital day in contrast to $54 \%$ of patients whose imaging denoted significant cranial pathology. This meant that those without significant cranial pathology were associated with 5 times the odds of an avoidable transfer than patients with notable cranial pathology (OR 5.3, 95\% CI 2.64-10.71, p $<0.001$ ). Although $5.2 \%$ of transfers needed neurosurgical intervention, no such cases were counted among those with isolated, nondisplaced skull fractures or those with negative imaging. It has been previously observed that neurologically intact patients can typically be discharged without hospital admission following observation in the ED after a normal head CT scan ${ }^{35}$ or one revealing only an isolated linear skull fracture. ${ }^{3,39}$
A review by White et al. ${ }^{47}$ of 438 patients transferred to a Level I facility for an isolated, linear, nondisplaced skull fracture in the absence of multisystem trauma found that all patients recovered with treatment of symptoms, and none required neurosurgical intervention, leading the authors of that paper to conclude that transfer to a higherlevel trauma facility is not warranted in this population. Several studies have even suggested that isolated skull fractures may not even require hospital admission, but a complete nonaccidental trauma workup is required. . $^{37,38}$ White et al ${ }^{47}$ documented a perioperative seizure rate of $1.4 \%$, lower than our rate of $5.7 \%$ among avoidable transfers, perhaps due to a misclassification of convulsions as seizures in our chart database. Of note, their rate of repeat CT scans, including those for displaced fractures, was only $6.8 \%$, in contrast to our rate of $18.6 \%$. Our findings lend further credence to conservatively managing this patient population without transfer in addition to patients with negative imaging, whereas more aggressive transfer of pediatric patients with a positive CT scan remains reasonable, particularly in light of $11 \%$ of patients with notable CT cranial pathology undergoing neurosurgical intervention.

We noticed a trend for possible overutilization of the PICU, to which $56 \%$ of PATs were initially admitted. This overutilization was particularly stark in the patients with isolated, nondisplaced skull fracture, of whom $60.5 \%$ were admitted to the PICU initially but only $4.7 \%$ remained after 1 day. Fenton et al. ${ }^{14}$ observed that $60 \%$ of preventable admissions to the PICU were for isolated head injury and suggested that critical care-level attention may not be necessary in many cases. Varano et al ${ }^{44}$ noted that $30 \%$ of patients with isolated cerebral contusions were admitted to the PICU, which was unnecessary in the presence of smaller contusions. This use of the PICU may represent the frequency of neurological checks requested by the admitting hospital team, but the need for PICU admission, as with transfer, should be contextualized within the clinical picture of the patient. Specifically, headache, loss of consciousness, and nonfocal neurological deficits were associated with necessary patient transfers, yet only loss of consciousness and nonfocal neurological deficits were associated with prolonged PICU stay. These findings are consistent with prior studies that emphasize that the pathology revealed on head CT must be interpreted within the clinical picture of the patient when determining the duration or level of hospitalization. $3,23,44$

Certain constellations of imaging features, GCS scores, and neurological statuses had a particularly strong relationship with potentially unavoidable transfers. We noted that 29 patients were transferred with negative imaging and a GCS score of 15, with no reported seizures or loss of consciousness. Of these, 27 (93\%) were discharged within 24 hours; the 2 remaining patients were discharged within 48 hours without ICU admission, surgical intervention, or repeat imaging. Among 62 patients transferred with a GCS score of 15 , no reported seizures or loss of consciousness, and either negative imaging or imaging that demonstrated only a linear, nondisplaced skull fracture, 57 (90\%) were discharged within 24 hours; the 5 remaining patients were discharged within 48 hours without undergoing sur- 
gical intervention. In contrast, 34 patients were transferred with a positive head CT scan and either a GCS score $\leq$ 14 or with reported loss of consciousness. Among them, $25(74 \%)$ were unavoidable transfers, including $7(21 \%)$ requiring neurosurgical interventions. Although our sample size is too small to draw definitive conclusions, these observations may inform the development of a more rigorous transfer algorithm in the future while guiding clinical decision-making in the short term.

Since children are routinely scanned at outside hospitals prior to transfer, we examined the need for transfer in this subset. We do not advocate aggressive CT imaging for either the initial workup of head injury or prior to transfer. Typically, we advocate that referring institutions hold off on imaging and, if they intend to transfer a child regardless of imaging findings, allow us to evaluate the need upon the patient's arrival. Our findings are consistent with the results of Kupperman et al., ${ }^{22}$ who proposed a detailed algorithm identifying children at low risk for clinically important TBI to obviate acquisition of head CT scans in this radiosensitive population. Clinicians must consider the entire clinical picture when evaluating TBI and not reflexively order head CT scans in the pediatric population if they do not suspect intracranial injury.

To better manage the balance between the benefits of specialized pediatric care and the systemic costs of overtriage, the use of telemedicine has been increasingly advocated in the management of pediatric emergencies. ${ }^{15,24,48}$ The use of telemedicine in neurosurgery has been shown in smaller studies to reduce potential transfers by $21 \%$ $44 \%, 5,20,29$ with the additional benefit of recommending management changes independent of transfer in $44 \%$ of patients as well. ${ }^{29}$ In one study, ${ }^{12} 6 \%$ of patients $\geq 10$ years of age with mild head injuries observed at a peripheral hospital with neurosurgical consults available via telemedicine ultimately required transfer for operation, and the unfavorable outcome rate was similar to that in patients observed in a neurosurgical unit once adjusted for propensity score. A second study ${ }^{4}$ observed that $4.1 \%$ of selected head-injured patients, which included patients $<10$ years of age, initially managed at a Level II facility with neurosurgical consult available via teleradiology, would undergo transfer to a Level I facility. Telemedicine may have a singularly beneficial role in the management of pediatric neurosurgical cases, where a combination of factors based on the importance of pediatric TBI, ${ }^{34}$ belief in the superiority of pediatric-focused treatment centers, ${ }^{33,34}$ evidence of improved outcomes at centers with a high-volume of select neurosurgical cases, ${ }^{6}$ the benefit to neurocritically ill patients of specialized care by neurocritical care staffs, ${ }^{42}$ and a widening dearth of adequate neurosurgical coverage $^{7}$ could contribute to significant overtriage of the pediatric neurosurgical population.

This study is subject to multiple limitations. First, the perspective of the study is that of the receiving hospital, and we are unable to compare our findings to the cohort of patients not transferred from the referring hospital. Consequently, we were unable to assess what percentage of patients were evaluated at the transferring facility but not transferred for avoidable neurosurgical care. As several tertiary care centers exist within the same catchment area as ours, pediatric patients are not uniformly routed to one center for care, but we were unable to assess the number or characteristics of pediatric patients routed elsewhere. The retrospective nature of the study and the study's perspective as the receiving hospital also limited our ability to fully assess the context of the transfer and duration of hospitalization. We utilized coding to identify applicable cases, but coding alone may not capture the reason behind the referring facility's transfer and is itself vulnerable to inaccuracies. Although we excluded transfers from pediatrician offices and urgent care centers, we were limited in further assessing the qualifications and capacities of the transferring hospital. We were also limited in our ability to assess the grade or accuracy of radiological pathology as reported by the referring facility, as well as the extent of pretransfer workup. Some transfers may have been "potentially avoidable" from a surgical perspective but necessary due to an appropriate need for a neurology consult or due to the pediatric ward at the transferring hospital. Assuming all cases with reported intracranial pathology, focal or nonfocal neurological deficit, headache, loss of consciousness, amnesia, seizure, or emesis were unavoidable due to factors at the transferring hospital, $22 \%$ of cases (42/192) would constitute potentially avoidable transfers, which suggests that, at a minimum, 1 out of 5 transfers is avoidable.

Future studies should follow patients longitudinally from the hospital of transfer to the receiving hospital to correlate the exact impetus for triage (e.g., discomfort managing pediatric patients, neurosurgical management, unavailable consult, lack of pediatric wards, etc.) and the subsequent care received (duration of admission, imaging and interventions performed, medications given, consults provided, and level of care). Studies should continue to examine whether the type and degree of cranial pathology revealed on outside hospital CT scans can be associated with safe nontransfer or remote management.

\section{Conclusions}

Seventy percent of interfacility transfers for pediatric brain trauma in the absence of other systemic injuries warranting surgical intervention do not require neurosurgical intervention and patients are discharged the following hospital day. No patients transferred with isolated, nondisplaced skull fractures or negative $\mathrm{CT}$ imaging required neurosurgical intervention, and $86 \%$ were discharged the day after admission. In contrast, $11 \%$ of patients with CT scans indicative of cranial pathology required neurosurgical intervention. Clinical signs and symptoms associated with necessary transfer include headache, loss of consciousness, and nonfocal deficits. Patients 6 years of age and younger tend to be aggressively triaged. Potentially avoidable transfers have high rates of repeat imaging (19\%) and PICU admission (56\%), even when outside hospital imaging is negative or reveals only an isolated, nondisplaced skull fracture. We recommend more judicious transfer and management of patients, including those 6 years of age and younger, with negative imaging or isolated, nondisplaced skull fractures, particularly in the absence of neurological deficits. 


\section{References}

1. American College of Surgeons Committee on Trauma: Resources for Optimal Care of the Injured Patient. Chicago: American College of Surgeons, 2014 (https://www.facs.org/ / media/files/quality\%20programs/trauma/vrc\%20resources/ resources\%20for\%20optimal\%20care.ashx) [Accessed June $1,2018]$

2. Amini R, Lavoie A, Moore L, Sirois MJ, Emond M: Pediatric trauma mortality by type of designated hospital in a mature inclusive trauma system. J Emerg Trauma Shock 4:12-19, 2011

3. Arrey EN, Kerr ML, Fletcher S, Cox CS Jr, Sandberg DI: Linear nondisplaced skull fractures in children: who should be observed or admitted? J Neurosurg Pediatr 16:703-708, 2015

4. Ashkenazi I, Zeina AR, Kessel B, Peleg K, Givon A, Khashan T, et al: Effect of teleradiology upon pattern of transfer of head injured patients from a rural general hospital to a neurosurgical referral centre: follow-up study. Emerg Med J 32:946-950, 2015

5. Bailes JE, Poole CC, Hutchison W, Maroon JC, Fukushima T: Utilization and cost savings of a wide-area computer network for neurosurgical consultation. Telemed J 3:135-139, 1997

6. Boogaarts HD, van Amerongen MJ, de Vries J, Westert GP, Verbeek AL, Grotenhuis JA, et al: Caseload as a factor for outcome in aneurysmal subarachnoid hemorrhage: a systematic review and meta-analysis. J Neurosurg 120:605-611, 2014

7. Byrne RW, Bagan BT, Slavin KV, Curry D, Koski TR, Origitano TC: Neurosurgical emergency transfers to academic centers in Cook County: a prospective multicenter study. Neurosurgery 62:709-716, 2008

8. Ciesla DJ, Sava JA, Street JH III, Jordan MH: Secondary overtriage: a consequence of an immature trauma system. J Am Coll Surg 206:131-137, 2008

9. Con J, Long D, Sasala E, Khan U, Knight J, Schaefer G, et al: Secondary overtriage in a statewide rural trauma system. J Surg Res 198:462-467, 2015

10. Demetriades D, Martin M, Salim A, Rhee P, Brown C, Chan L: The effect of trauma center designation and trauma volume on outcome in specific severe injuries. Ann Surg 242:512-519, 2005

11. Esposito TJ, Crandall M, Reed RL, Gamelli RL, Luchette FA: Socioeconomic factors, medicolegal issues, and trauma patient transfer trends: Is there a connection? J Trauma 61:1380-1388, 2006

12. Fabbri A, Servadei F, Marchesini G, Stein SC, Vandelli A: Observational approach to subjects with mild-to-moderate head injury and initial non-neurosurgical lesions. J Neurol Neurosurg Psychiatry 79:1180-1185, 2008

13. Faul M, Wald MM, Sullivent EE, Sasser SM, Kapil V, Lerner EB, et al: Large cost savings realized from the 2006 Field Triage Guideline: reduction in overtriage in U.S. trauma centers. Prehosp Emerg Care 16:222-229, 2012

14. Fenton SJ, Campbell SJ, Stevens AM, Zhang C, Presson AP, Lee JH: Preventable pediatric intensive care unit admissions over a 13 -year period at a level 1 pediatric trauma center. $\mathbf{J}$ Pediatr Surg 51:1688-1692, 2016

15. Fenton SJ, Lee JH, Stevens AM, Kimbal KC, Zhang C, Presson AP, et al: Preventable transfers in pediatric trauma: a 10year experience at a level I pediatric trauma center. J Pediatr Surg 51:645-648, 2016

16. Garwe T, Cowan LD, Neas B, Cathey T, Danford BC, Greenawalt P: Survival benefit of transfer to tertiary trauma centers for major trauma patients initially presenting to nontertiary trauma centers. Acad Emerg Med 17:1223-1232, 2010

17. Gattu RK, Teshome G, Cai L, Wright C, Lichenstein R: Interhospital pediatric patient transfers-factors influencing rapid disposition after transfer. Pediatr Emerg Care 30:26-30, 2014

18. Glance LG, Osler TM, Mukamel DB, Dick AW: Impact of trauma center designation on outcomes: is there a difference between Level I and Level II trauma centers? J Am Coll Surg 215:372-378, 2012

19. Goh KY, Lam CK, Poon WS: The impact of teleradiology on the inter-hospital transfer of neurosurgical patients. Br J Neurosurg 11:52-56, 1997

20. Goldstein SD, Van Arendonk K, Aboagye JK, Salazar JH, Michailidou M, Ziegfeld S, et al: Secondary overtriage in pediatric trauma: can unnecessary patient transfers be avoided? J Pediatr Surg 50:1028-1031, 2015

21. Kissoon N, Dreyer J, Walia M: Pediatric trauma: differences in pathophysiology, injury patterns and treatment compared with adult trauma. CMAJ 142:27-34, 1990

22. Kupperman N, Holmes JF, Dayan PS, Hoyle JD Jr, Atabaki SM, Holubkov R, et al: Identification of children at very low risk of clinically-important brain injuries after head trauma: a prospective cohort study. Lancet 374:1160-1170, 2009

23. Lefort R, Hunter JV, Cruz AT, Caviness AC, Luerssen TG, Adekunle-Ojo A: Utility of emergency department observation units for neurologically intact children with head CT abnormalities secondary to acute closed head injury. Pediatr Emerg Care 33:161-165, 2017

24. Leung A, Bonasso P, Lynch K, Long D, Vaughan R, Wilson A, et al: Pediatric secondary overtriage in a statewide trauma system. Am Surg 82:763-767, 2016

25. Li J, Monuteaux MC, Bachur RG: Interfacility transfers of noncritically ill children to academic pediatric emergency departments. Pediatrics 130:83-92, 2012

26. Lynch KT, Essig RM, Long DM, Wilson A, Con J: Nationwide secondary overtriage in level 3 and level 4 trauma centers: are these transfers necessary? J Surg Res 204:460-466, 2016

27. MacKenzie EJ, Rivara FP, Jurkovich GJ, Nathens AB, Frey $\mathrm{KP}$, Egleston BL, et al: A national evaluation of the effect of trauma-center care on mortality. N Engl J Med 354:366378,2006

28. Mohr NM, Harland KK, Shane DM, Miller SL, Torner JC: Potentially avoidable pediatric interfacility transfer is a costly burden for rural families: a cohort study. Acad Emerg Med 23:885-894, 2016

29. Moya M, Valdez J, Yonas H, Alverson DC: The impact of a telehealth web-based solution on neurosurgery triage and consultation. Telemed J E Health 16:945-949, 2010

30. Newgard CD, McConnell KJ, Hedges JR, Mullins RJ: The benefit of higher level of care transfer of injured patients from nontertiary hospital emergency departments. J Trauma 63:965-971, 2007

31. Osen HB, Bass RR, Abdullah F, Chang DC: Rapid discharge after transfer: risk factors, incidence, and implications for trauma systems. J Trauma 69:602-606, 2010

32. Osler TM, Vane DW, Tepas JJ, Rogers FB, Shackford SR, Badger GJ: Do pediatric trauma centers have better survival rates than adult trauma centers? An examination of the National Pediatric Trauma Registry. J Trauma 50:96-101, 2001

33. Oyetunji TA, Haider AH, Downing SR, Bolorunduro OB, Efron DT, Haut ER, et al: Treatment outcomes of injured children at adult level 1 trauma centers: are there benefits from added specialized care? Am J Surg 201:445-449, 2011

34. Petrosyan M, Guner YS, Emami CN, Ford HR: Disparities in the delivery of pediatric trauma care. J Trauma 67 (2 Suppl):S114-S119, 2009

35. Plackett TP, Asturias S, Tadlock M, Wright F, Ton-That H, Demetriades D, et al: Re-evaluating the need for hospital admission and observation of pediatric traumatic brain injury after a normal head CT. J Pediatr Surg 50:1758-1761, 2015

36. Potoka DA, Schall LC, Gardner MJ, Stafford PW, Peitzman 
$\mathrm{AB}$, Ford HR: Impact of pediatric trauma centers on mortality in a statewide system. J Trauma 49:237-245, 2000

37. Powell EC, Atabaki SM, Wootton-Gorges S, Wisner D, Mahajan P, Glass T, et al: Isolated linear skull fractures in children with blunt head trauma. Pediatrics 135:e851-e857, 2015

38. Reuveni-Salzman A, Rosenthal G, Poznanski O, Shoshan Y, Benifla M: Evaluation of the necessity of hospitalization in children with an isolated linear skull fracture (ISF). Childs Nerv Syst 32:1669-1674, 2016

39. Rollins MD, Barnhart DC, Greenberg RA, Scaife ER, Holsti M, Meyers RL, et al: Neurologically intact children with an isolated skull fracture may be safely discharged after brief observation. J Pediatr Surg 46:1342-1346, 2011

40. Sathya C, Alali AS, Wales PW, Scales DC, Karanicolas PJ, Burd RS, et al: Mortality among injured children treated at different trauma center types. JAMA Surg 150:874-881, 2015

41. Sorensen MJ, von Recklinghausen FM, Fulton G, Burchard KW: Secondary overtriage: the burden of unnecessary interfacility transfers in a rural trauma system. JAMA Surg 148:763-768, 2013

42. Suarez JI, Zaidat OO, Suri MF, Feen ES, Lynch G, Hickman $\mathrm{J}$, et al: Length of stay and mortality in neurocritically ill patients: impact of a specialized neurocritical care team. Crit Care Med 32:2311-2317, 2004

43. Tang A, Hashmi A, Pandit V, Joseph B, Kulvatunyou N, Vercruysse G, et al: A critical analysis of secondary overtriage to a Level I trauma center. J Trauma Acute Care Surg 77:969-973, 2014

44. Varano P, Cabrera KI, Kuppermann N, Dayan PS: Acute outcomes of isolated cerebral contusions in children with Glasgow Coma Scale scores of 14 to 15 after blunt head trauma. J Trauma Acute Care Surg 78:1039-1043, 2015
45. Wang NE, Saynina O, Vogel LD, Newgard CD, Bhattacharya J, Phibbs CS: The effect of trauma center care on pediatric injury mortality in California, 1999 to 2011. J Trauma Acute Care Surg 75:704-716, 2013

46. Webman RB, Carter EA, Mittal S, Wang J, Sathya C, Nathens AB, et al: Association between trauma center type and mortality among injured adolescent patients. JAMA Pediatr 170:780-786, 2016

47. White IK, Pestereva E, Shaikh KA, Fulkerson DH: Transfer of children with isolated linear skull fractures: is it worth the cost? J Neurosurg Pediatr 17:602-606, 2016

48. Yamamoto LG: Access to optimal emergency care for children. Pediatrics 119:161-164, 2007

\section{Disclosures}

Dr. Hwang reports serving on the speaker's bureaus for Zimmer Biomet and NuVasive.

\section{Author Contributions}

Conception and design: Hwang, Mackel. Acquisition of data: Mackel, Morel, Park, Sweeney, Heller. Analysis and interpretation of data: Hwang, Mackel. Drafting the article: Hwang, Mackel. Critically revising the article: Hwang, Mackel, Winer, Rideout, Riesenburger. Reviewed submitted version of manuscript: all authors. Approved the final version of the manuscript on behalf of all authors: Hwang. Statistical analysis: Mackel. Study supervision: Hwang.

\section{Correspondence}

Steven W. Hwang: Shriners Hospitals for Children, Philadelphia, PA. stevenhwang@hotmail.com. 